\title{
AC 2010-1533: BALANCING THE DEMAND FOR TEACHING AND SPONSORED RESEARCH ACTIVITY
}

\section{Daniel Johnson, Rochester Institute of Technology}

Daniel P. Johnson is an Associate Professor and Department Chair in the Manufacturing and Mechanical Engineering Technology/Packaging Science Department at Rochester Institute of Technology. He teaches courses in manufacturing operations, automation, robotics, computer aided manufacturing and operations strategy. Prior to joining the MMET/PS Faculty he was Director of RIT's Manufacturing Management and Leadership Program, Engineering Manager for the Center for Integrated Manufacturing Studies, and an Advanced Manufacturing Engineer for Allied Signal. He has a Master of Engineering Degree in Manufacturing and a BS in Industrial and Manufacturing Engineering from RIT as well as an AAS in Engineering Science from Hudson Valley Community College.

\section{Brian Thorn, Rochester Institute of Technology}

Brian K. Thorn is an Associate Professor in the Industrial and Systems Engineering Department at the Rochester Institute of Technology in New York. He received a B.S. in Industrial Engineering from the Rochester Institute of Technology, an M.S. and Ph.D. from the Georgia Institute of Technology. His research interests include sustainable product and process design, life cycle analysis and applied statistical methods. 


\title{
Balancing the Demand for Teaching and Sponsored Research Activity
}

\begin{abstract}
Academic departments routinely struggle to strike a balance between two competing needs:

- the need to deliver classes with capacity and frequency sufficient to meet student demand, and

- the need to conduct sponsored research at a level to support meaningful scholarly contributions by the faculty

Universities and departments have a strategic decision to make when it comes to setting a goal for what percentage of the organization's efforts should be dedicated to teaching vs. research. Some may be comfortable with more than half of their total faculty efforts dedicated to sponsored research, while others might find this level intolerable. After the strategic decision is made, the stochastic nature of these activities can continue to present a serious challenge to administrators attempting to achieve and maintain the desired balance of activity. This paper outlines an effort to build a model which can be used to examine the variability inherent in such systems, and to use past experience to plan for likely future outcomes. The model generates information on the likelihood of an oversupply or shortage of faculty capacity and the potential that organizational metrics like percentage of adjunct faculty use could fall outside acceptable ranges.
\end{abstract}

\section{Introduction and Background}

Academic institutions must address a number of constituencies along a variety of dimensions as they seek to fulfill their missions. The mission statement for the Rochester Institute of Technology (RIT), the institution that the authors will address here, reads in part:

"Our mission is to provide technology-based educational programs for personal and professional development. We rigorously pursue new and emerging career areas. We develop and deliver curricula and advance scholarship relevant to emerging technologies and social conditions."

At this institution, there is a good deal of variability among departments in terms of how their activities are expected to support the pursuit of "new and emerging career areas" and "advance scholarship relevant to emerging technologies". However, in the engineering and technology oriented programs, there is a clear expectation that support of these dimensions of RIT's mission should come, in large part, from scholarly research, preferably funded research.

At the academic department level there is an ongoing challenge to provide significant scholarly research opportunities for faculty. As a matter of faculty and departmental advancement it is 
critical to identify funding agencies and corporations with research goals that match department and faculty interests. White papers, research proposals, responses to requests for proposal, and contracts can then be prepared and presented to potential funding agencies. In the department considered in this study, it is common to have more than one million dollars in proposals of this kind under review at funding agencies. This situation can be quite stressful for department leadership responsible for scheduling faculty and resources necessary to deliver on the teaching, research and service responsibilities of the department. Often, faculty and the department are attempting to achieve a specific minimum amount of funding, so there is a temptation to put out as many proposals as possible. However, there is always a possibility that entirely too many funding request will be approved, creating a situation where resources such as faculty time, graduate students, laboratory equipment and space are in such short supply that the department is unable to meet instructional demands. Teaching demands in the department under study have been shown to have significant variability. ${ }^{[1]}$ When coupled with fluctuations in the level of sponsored research awards, this variability will lead to significant challenges in meeting departmental obligations.

This work is based on a series of conversations the authors had regarding the nature of this 'numbers game' and is an effort to better understand the nature of the variability associated with this common departmental challenge. In this paper a basic model will be constructed and applied to a set of realistic department data. In all cases the analysis considers only pending proposals that may add additional demands on the department; existing sponsored research activity and rejected proposals are not included. A simulation tool is utilized to help visualize variability in the metrics of interest. The tool used here, Crystal Ball, is an enhancement to Microsoft's Excel spreadsheet system that augments its ability to incorporate stochastic inputs and record and display probabilistic outputs. The figures here result from aggregating the results of 1,000,000 distinct trials for each of the scenarios considered.

\section{Resources and Metrics to Balance}

The focus of this study is an Engineering Technology Department which is not organized like many departments in research universities. There is not a specific category of research faculty. All tenured and tenure track faculty are expected to perform scholarly work, but this may or may not include sponsored research at any given time. While some faculty work plans are more focused on research than others, in most cases when research projects are approved, teaching assignments must be offloaded to free up the required people. Lecturers and adjunct faculty fill this need, but it is possible to outstrip the existing supply, and often difficult to bring on new talent with short notice. In the tables and models that follow the number of individual faculty in each proposal, the full time equivalent amount of effort promised in the project plan, the equivalent effort of graduate students, and the total amount of funding is identified. It should be noted that the total amount of funding may not be a direct indicator of the faculty and graduate student effort promised for each project. 


\section{A Sample Case}

At a basic level we can consider a department with five pending proposals.

\begin{tabular}{|c|c|}
\hline Proposal & Funding (\$) \\
\hline A & $\$ 124,000$ \\
\hline B & $\$ 211,695$ \\
\hline C & $\$ 665,644$ \\
\hline D & $\$ 4,225$ \\
\hline E & $\$ 50,000$ \\
\hline Total Pending & $\$ 1,055,564$ \\
\hline
\end{tabular}

Table 1: Pending Proposals

Based on Table 1 it is clear the department will receive additional funding of somewhere between zero and $\$ 1,055,564$. Within sponsored research circles the term 'hit rate' is often used to describe the success rate of proposals. So in this case a hit rate of $10 \%$ could indicate to some the department should expect approximately $\$ 105,500$ in total funding. If the dean in the area had challenged the department to produce $\$ 100,000$ in sponsored research funding, the situation may seem quite acceptable. However, if we consider the 'hit rate' to be the probability of acceptance for any one proposal, the situation is more complex. Potential outcomes include all or no proposals accepted, any single proposal accepted, and any combination accepted. In fact there are no scenarios which would meet the dean's goal of exactly $\$ 100,000$ in new funding. All available outcomes put the department under or over the stated goal. Exceeding the dean's expectations may not be a bad thing in this situation as long as the department actually has the capacity to undertake the required additional workload while maintaining high quality teaching, service and other activities. Given the distribution of pending proposals shown in Table 1 and a "hit rate" of $10 \%$ for each proposal, 32 possible funding combinations can arise (each of the 5 proposals may or may not be funded; this gives rise to $2^{5}=32$ possible scenarios). The total funding that could be awarded to the department under this scenario varies from a total of $\$ 0$ (which occurs with a probability of 0.59 ) to a total of $\$ 1,055,564$ (which occurs with a probability of 0.00001). Figure 1 shows the complete distribution of potential awards. Note, the chart is not able to display probabilities associated with many of the outcomes because those probabilities are very small $(<0.001)$. 


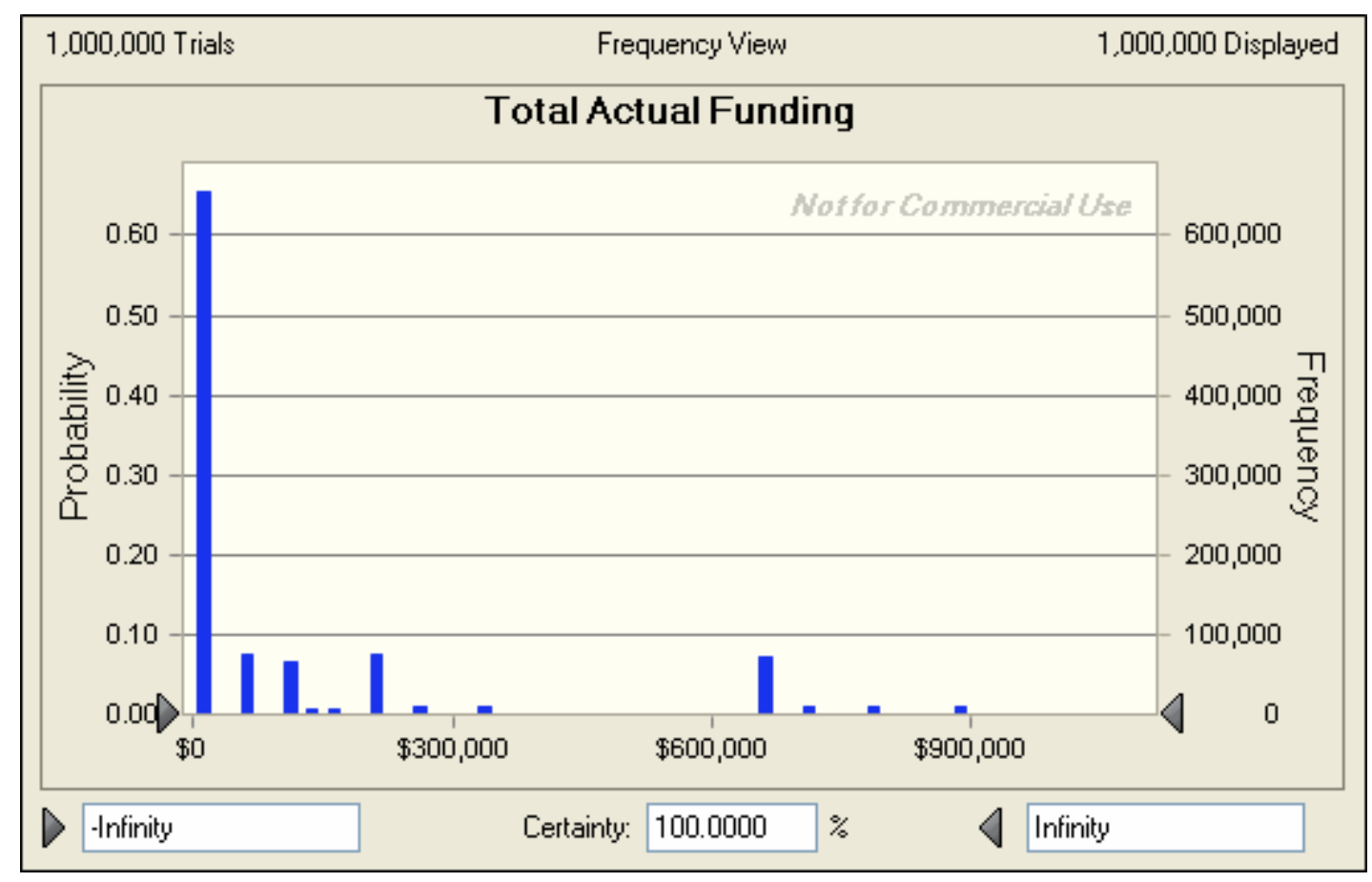

Figure 1

It may seem surprising to some that even with over a million dollars of proposals pending, the most likely outcome is zero new funding. A likely reaction is to start generating large quantities of new proposals which will make the model much more interesting and hopefully valuable as the numbers get larger.

\section{Adding Workload Considerations}

The simple model discussed above considers only total funding. The ability to actually carry out the proposed research work will be dependent on the ability to free up the resources necessary for the project. Faculty and graduate student time being the most immediate concern, we add these to the model next. The full time equivalent (FTE) effort required for research projects is often not directly correlated to the total amount of funding. Grant proposals can contain significant capital equipment items, subcontracts, indirect cost, cost-share and other items. So it is possible to have very large grant proposals with only minimal required effort from faculty and/or small project proposals with significant time commitment required from faculty and graduate students. The model below expands our simple example to include the number of department faculty working on the project, the yearly total full time equivalent (FTE) effort from faculty and the yearly full time equivalent effort from graduate students. 


\begin{tabular}{|c|c|c|c|c|}
\hline Proposal & Funding (\$) & \# of Faculty & FTE Faculty & $\begin{array}{c}\text { FTE Grad } \\
\text { Students }\end{array}$ \\
\hline A & 124,000 & 1 & 0.08 & 0 \\
\hline B & 211,695 & 1 & 0.21 & 2.0 \\
\hline C & 665,644 & 1 & 0.17 & 1.5 \\
\hline D & 4,225 & 1 & 0.04 & 0 \\
\hline E & 50,000 & 2 & 0.24 & 1.0 \\
\hline Total Pending & $1,055,564$ & & & \\
\hline
\end{tabular}

Table 2: Pending Proposals with Workload

Given the workload assignments indicated in Table 2 above, we can compute distributions for the number of faculty that will be assigned to sponsored projects, the total faculty FTE that will be devoted to conducting the research, and the total graduate student FTE that will be required to support the research. These distributions are shown in Figures 2, 3, and 4.

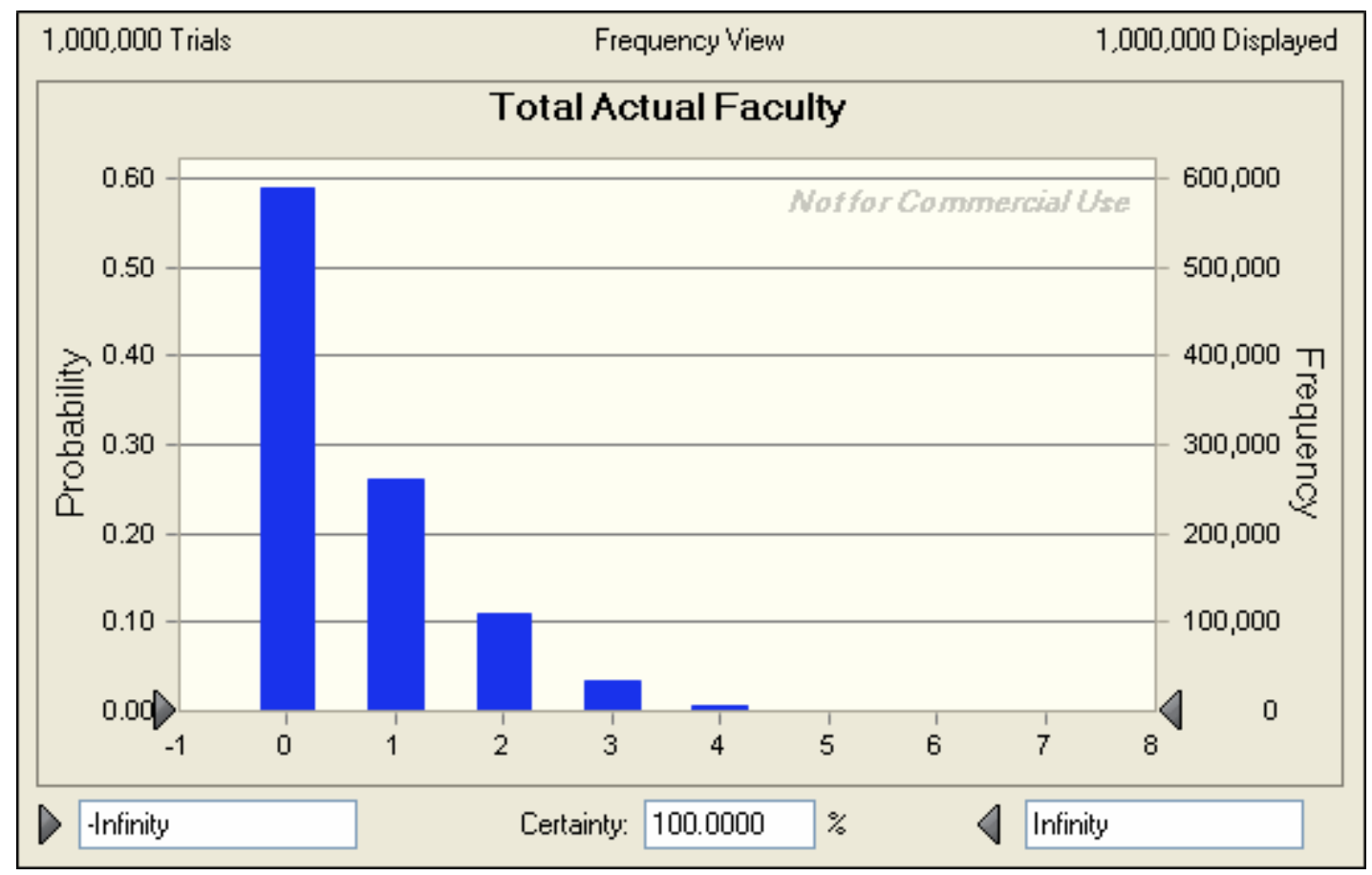

Figure 2

Department leadership may be upset to find that Figure 2 indicates that even with quite a few faculty members involved in sponsored research proposals, the most likely single outcome is no additional faculty will be working on projects. However, it is interesting to note that because 
some of the proposals involve multiple faculty members, it is conceivable to have multiple faculty members engaged in sponsored research, even if a small number of proposals are approved.

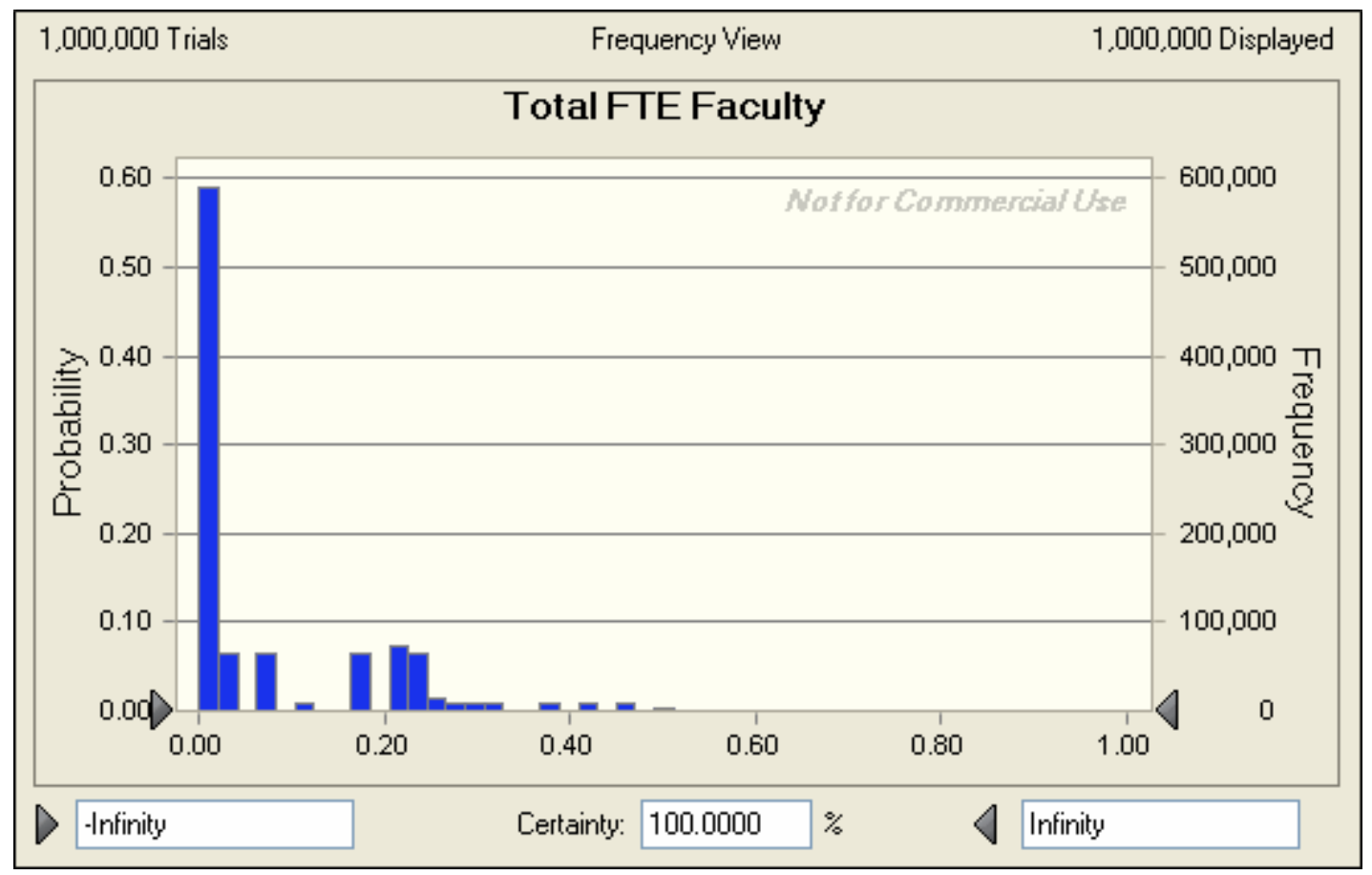

Figure 3

Figure 3 indicates that even with almost one million dollars of proposals outstanding we are unlikely to require a large amount of additional backfill instruction. However, for departments with a limited supply of possible adjunct or lecturer faculty, even the very low probability of requiring a 1/2 FTE faculty member could represent a significant concern. 


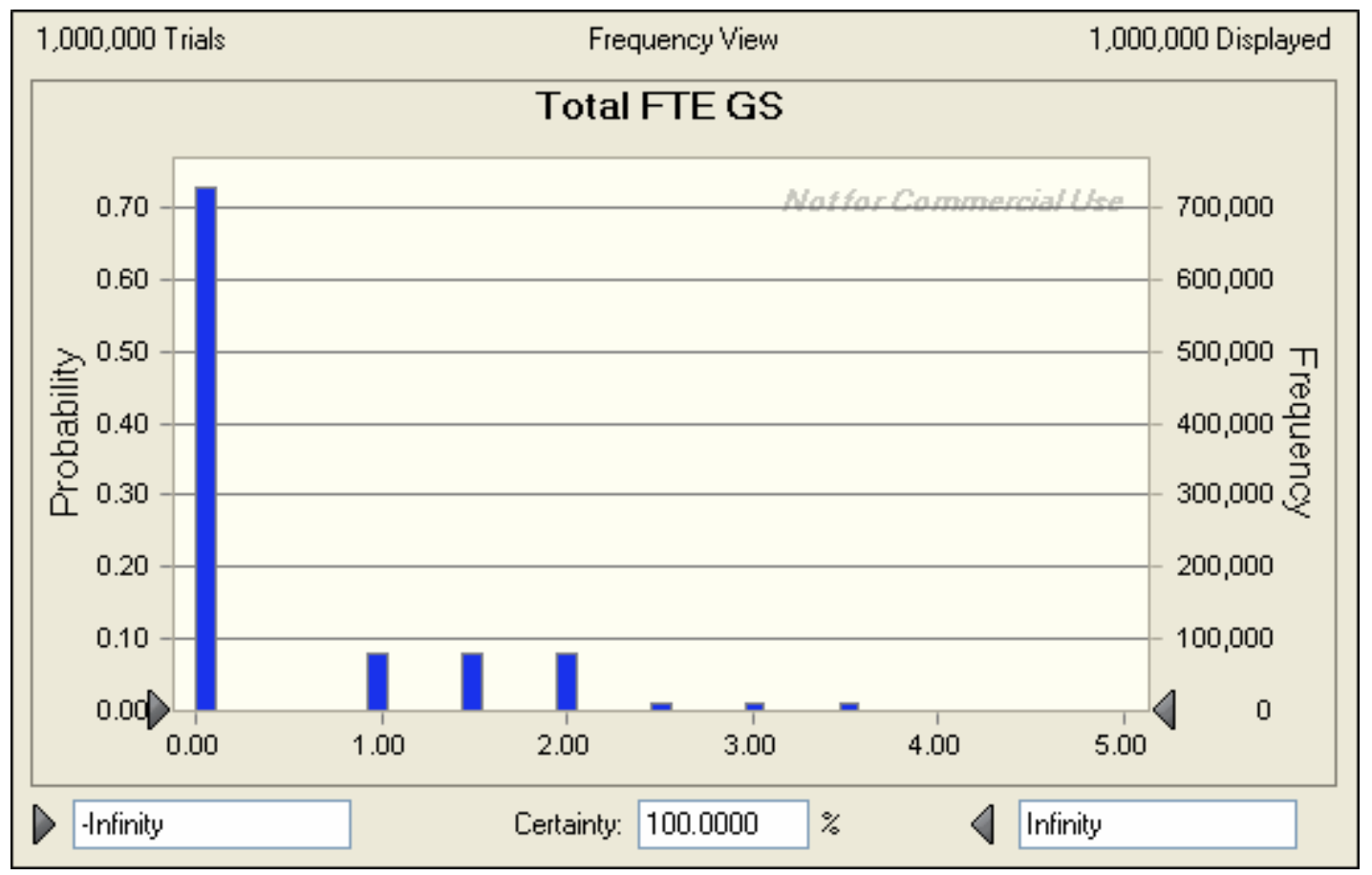

Figure 4

Figure 4 indicates that additional graduate students will probably not be needed. It also indicates that two available graduate students would be able to satisfy the department's needs in the vast majority of cases.

Of course the analysis offered here relies on a number of simplifying assumptions that make the problem tractable. For instance, the initial results are generated assuming that the probability of all sponsored projects under consideration is the same (0.10). Clearly, this is not usually the case. Funding from some sources is highly competitive resulting in lowered probabilities of awards. Other proposals may have been requested by longtime research clients and have much higher likelihood of approval. Altering the probabilities that proposals will be funded could either decrease or increase the variability of the system, depending upon whether there is more or less certainty associated with the awarding of proposals. Consider the award scenario in Table 3.

\begin{tabular}{|c|c|c|c|c|c|}
\hline Proposal & Funding (\$) & $\begin{array}{c}\text { Probability } \\
\text { of Funding }\end{array}$ & $\begin{array}{c}\text { \# of } \\
\text { Faculty }\end{array}$ & FTE Faculty & $\begin{array}{c}\text { FTE Grad } \\
\text { Students }\end{array}$ \\
\hline A & 124,000 & 0.02 & 1 & 0.08 & 0 \\
\hline B & 211,695 & 0.15 & 1 & 0.21 & 2.0 \\
\hline C & 665,644 & 0.1 & 1 & 0.17 & 1.5 \\
\hline D & 4,225 & 0.15 & 1 & 0.04 & 0 \\
\hline E & 50,000 & 0.02 & 2 & 0.24 & 1.0 \\
\hline Total Pending & $1,055,564$ & & & & \\
\hline
\end{tabular}

Table 3 
The probabilities assigned above might reflect a situation where funding proposals can be sorted into categories characterized by a relatively high probability of acceptance $(0.15)$, an average probability of acceptance (0.10), and a low probability of acceptance (0.02). Analysis of Figures 5-8 shows that there will be slightly more variability in the system outcomes relative to that observed under the previous, equal probability, scenario. Certainly other scenarios could be constructed where less variability would be observed.

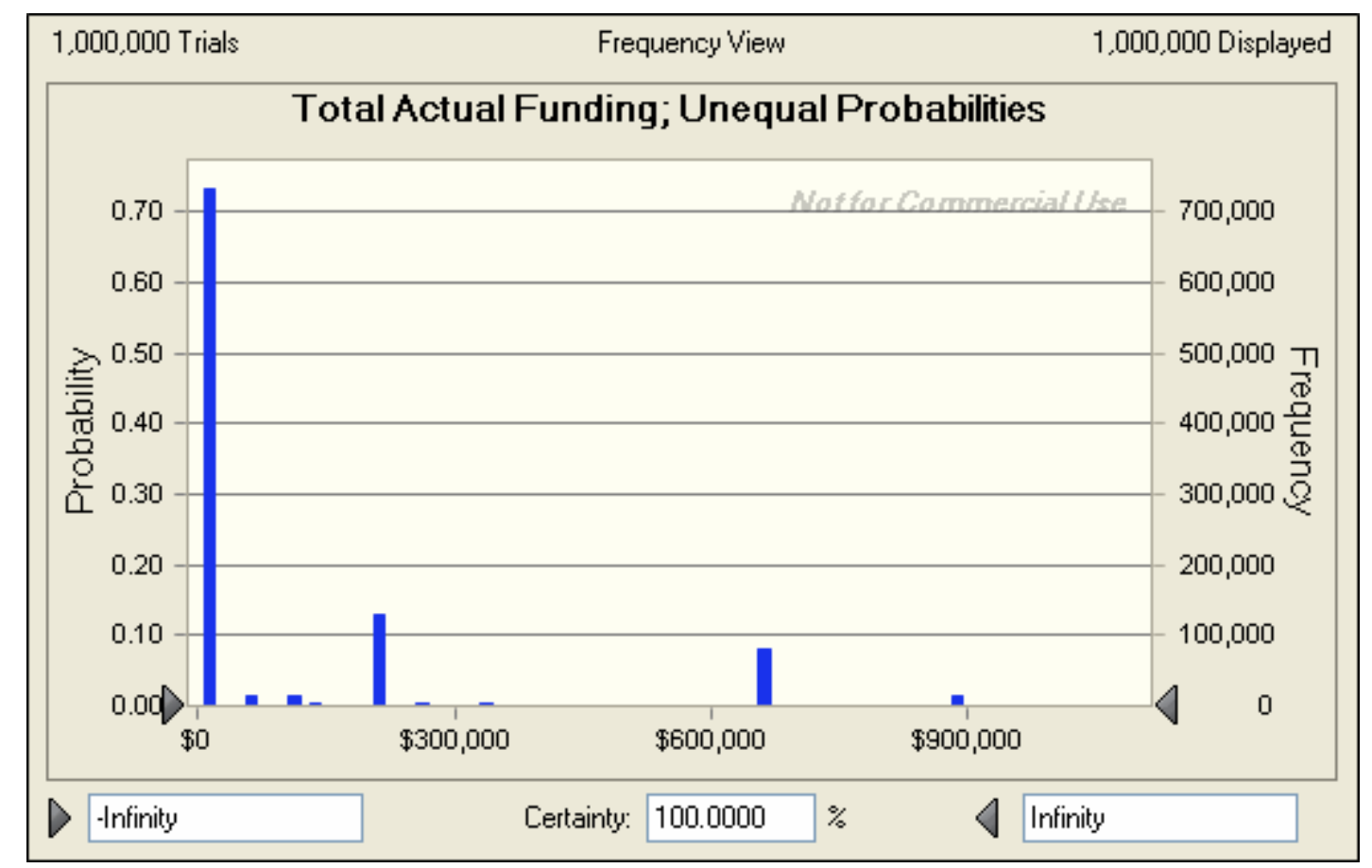

Figure 5

Figure 5 indicates the department is most likely to experience zero new funding for research. However it also shows that the next most likely funding levels are something around $\$ 250,000$ or around $\$ 600,000$. It is interesting to note there is very little chance of funding in-between those two ranges. Figures 6, 7 and 8 show similar results to the sample case reviewed earlier. The FTE levels for additional faculty and graduate students indicated by the analysis are reasonable amounts for the department to be able to provide on somewhat short notice. 


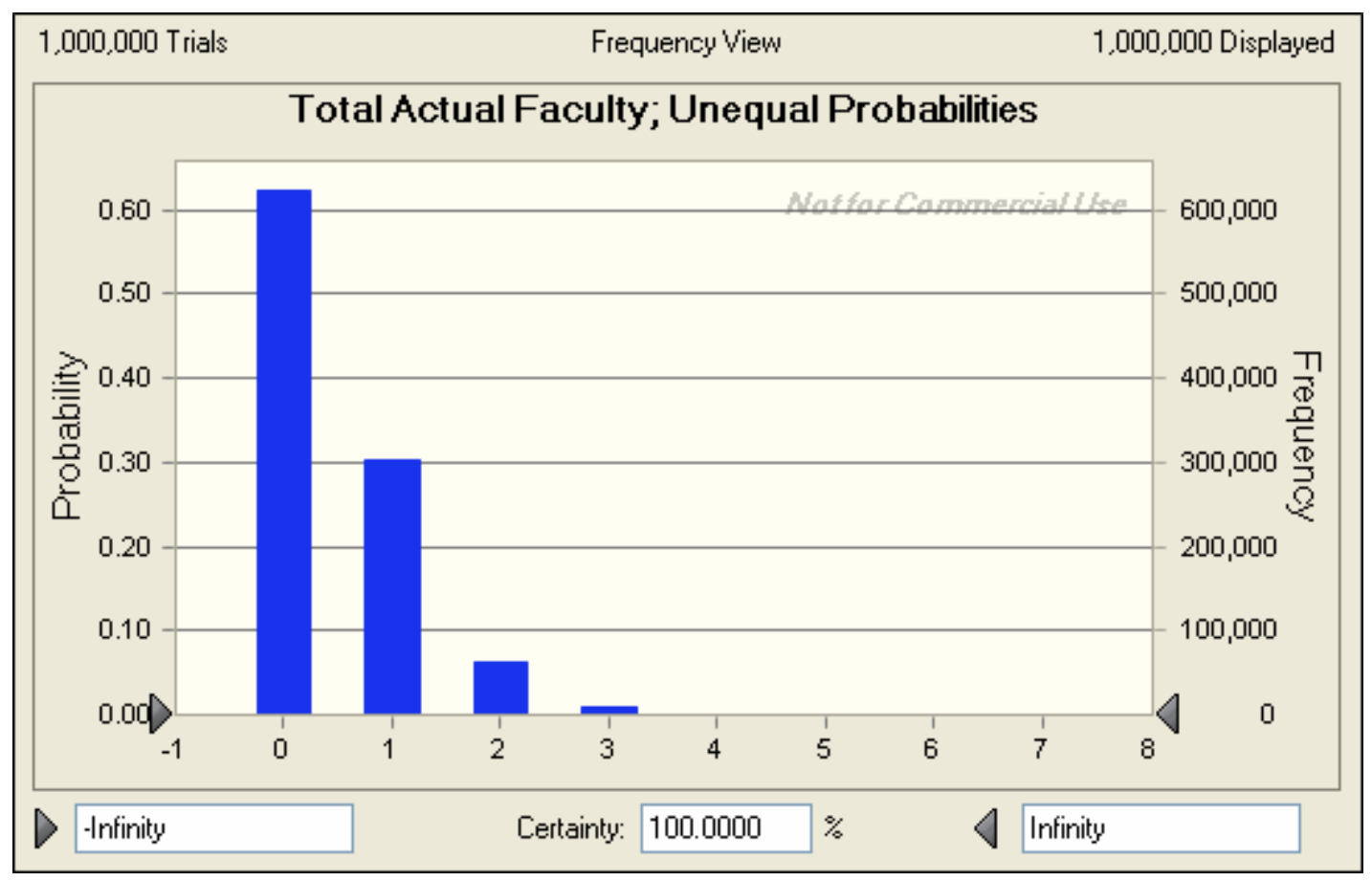

Figure 6

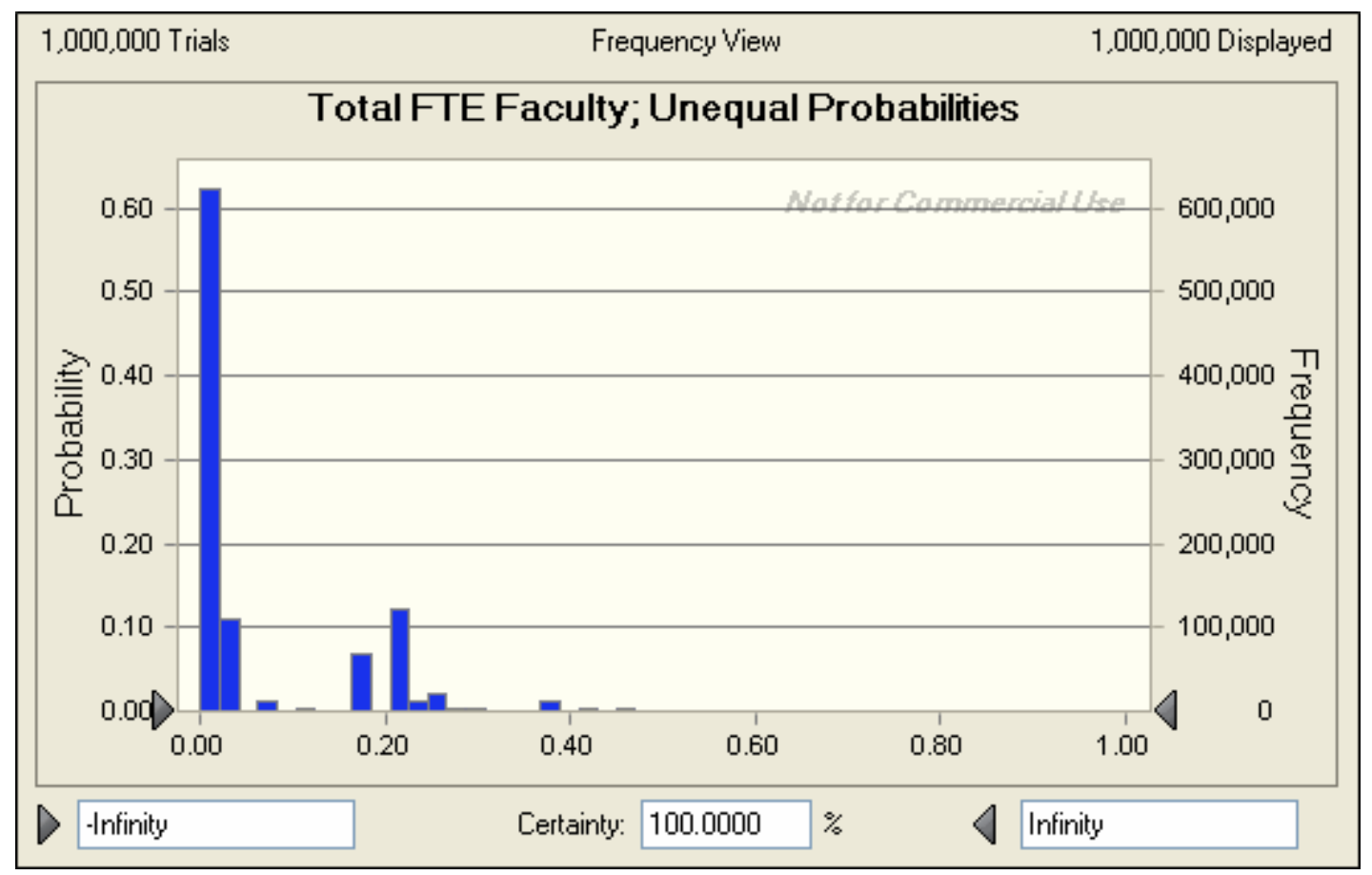

Figure 7

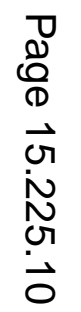




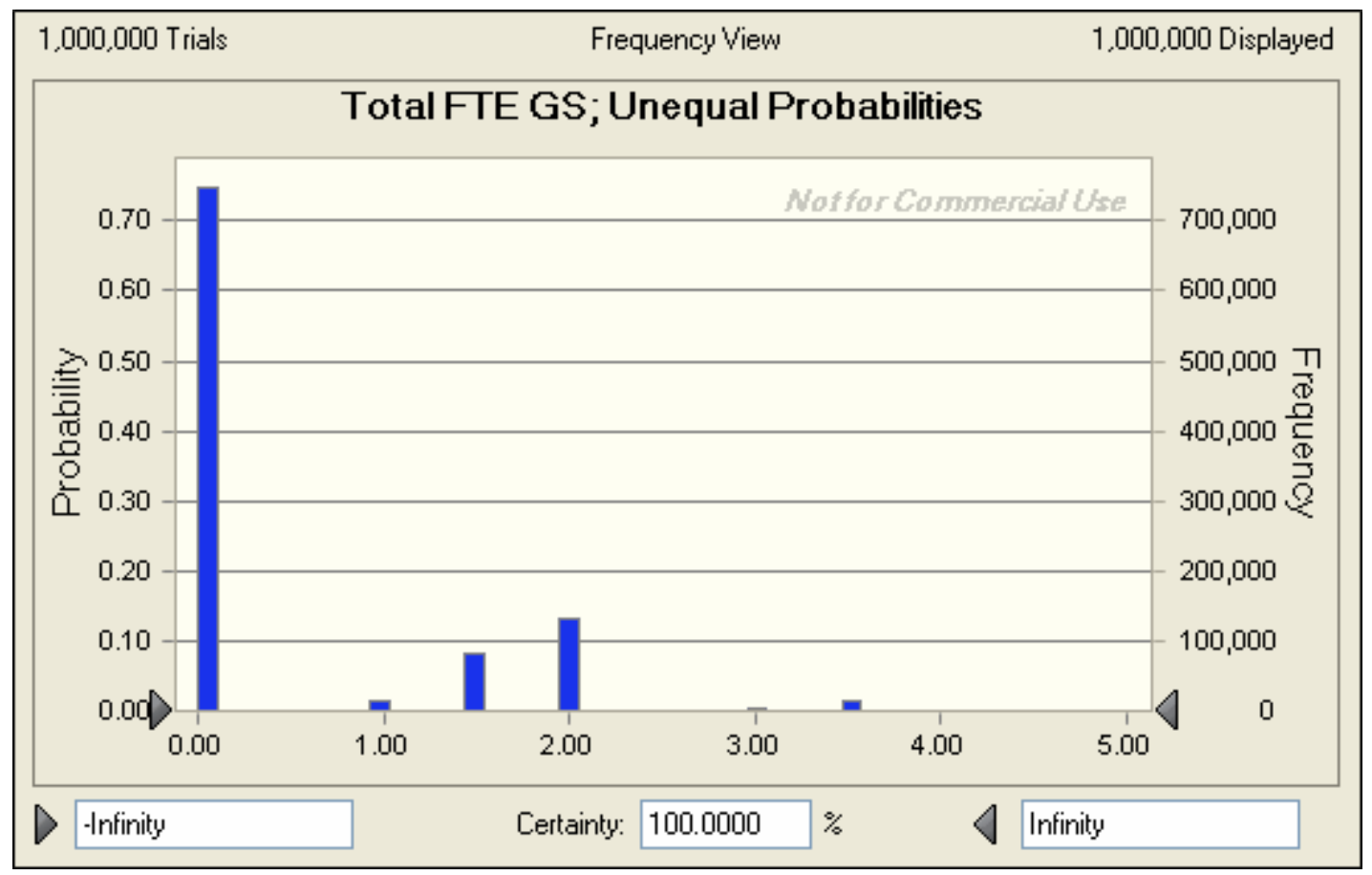

Figure 8

These results can also be used to determine probabilities which are particularly interesting from a management and planning perspective. For example Figure 5 indicates that the current probability the department will receive greater than $\$ 100,000$ in additional funding is 0.25 . Also Figure 7 shows that the current probability of needing $25 \%$ or greater FTE of additional faculty effort is 0.05 . Similar results can be determined for any of the resources studied.

\section{Conclusions}

Efforts to quantify the variability and likelihood of outcomes for pending research proposals proved valuable for department leadership. By quantifying impacts of the possible outcomes for the department, the analysis was able to provide a deeper understanding of a highly variable situation. The ability to estimate the likelihood of a specific future need, for example requiring one new full faculty FTE, should prove to be quite valuable. A second observation is that prior to developing this kind of model, the perception of department leaders was that potential of over one million dollars of pending proposals was very likely to cause a future shortage of resources. However, the analysis showed that the vast majority of likely outcomes are well within the feasible region for the department in terms of meeting the demand for additional teaching and graduate student resources. 


\section{Bibliography}

1. "Capacity and Resource Planning for an Engineering Technology Department”, Daniel P. Johnson, Brian K. Thorn, Proceedings of the 2009 American Society for Engineering Education Annual Conference \& Exposition

2. "Strategies for Enhancing the Scholarly Productivity of Engineering Technology Educators", Abi Aghayere, Proceedings of the 2004 American Society for Engineering Education Annual Conference \& Exposition

3. "Growing Research in a Traditionally Teaching-oriented College", Michael Murphy, Michael Dyrenfurth, Proceedings of the 2007 American Society for Engineering Education Annual Conference \& Exposition

4. "A Model to Assess and Balance Faculty Workload", David Gibson, Don Rabern, Vic Cundy Proceedings of the 2001 American Society for Engineering Education Annual Conference \& Exposition

5. "Graduate Student Perspectives of the Balance Between Research and Teaching - A Preliminary Report", William C. Dillard, Rhonda Buckley, James E. Groccia, Proceedings of the 2005 American Society for Engineering Education Annual Conference \& Exposition

6. "Match Supply and Demand in Service Industries", W. Earl Sasser, Harvard Business Review, 1976 